\title{
Nutritional and Antioxidant Potential of Common Vegetables in Pakistan
}

\author{
Sumra Naseer, Shabbir Hussain*, Zark Zahid \\ Department of Chemistry, Lahore Garrison University, DHA Phase VI, Lahore, Pakistan
}

ABSTRACT

Vegetables contain many important antioxidants and nutrients. Daucus carota $L$ (carrot) is rich in hydrophilic and lipophilic antioxidants and is a good source of carbohydrates, vitamins, and minerals such as $\mathrm{Ca}, \mathrm{Mg}, \mathrm{P}$, and Fe. It shows anti-carcinogenic, antioxidant, and immune boosting properties. It also provides protection against muscular degradation and development of senile cataract and reduces the risk of many diseases in humans. The nutritional value of Cucurbita pepo Linn (pumpkin) is attributed to the high level of carotenoids, carbohydrates, vitamins, other minerals. Pumpkin due to the presence of vitamin $\mathrm{B}$ complex, $\mathrm{Ca}$ and $\mathrm{P}$, provides protection against many acute and chronic diseases. Pumpkin peel and pulp are the good source of antioxidants, polyphenols, carotenoids, dietary fiber and minerals such as $\mathrm{P}$ and Fe. Pumpkin extract shows antioxidant, antimicrobial and other activities. Spinacia oleracea (spinach) is a good source of essential nutrients such as carotenoids, vitamins, and minerals $(P, K, M g)$. Its leaves contain carotenoids, polyphenols, flavonoids, and ascorbic acid. Fresh spinach extract shows antioxidant and antimicrobial activity. Solanum tuberosum (potato) is rich in starch, alkaloids, flavonoids, dietary fiber, and some other minerals $(\mathrm{K}, \mathrm{Mg}, \mathrm{Fe})$. Potato helps to overcome chronic and acute diseases and has an impact on blood pressure and gut health.

Keywords

Carrot, pumpkin, spinach, potato,

nutrients, antioxidant, vitamins.
*Address of Correspondence

shabchem786@gmail.com
Article info.

Received: June 9, 2018

Accepted: November 29, 2018

Cite this article: Naseer S, Hussain S, Zahid Z. Nutritional and Antioxidant Potential of Common

Vegetables in Pakistan. RADS J. Biol. Res. Appl. Sci. 2019; 10(1): 36-40.

This is an Open Access article distributed under the terms of the Creative Commons Attribution License (http://creativecommons.org/licenses/by/4.0), which permits unrestricted use, distribution, and reproduction in any medium, provided the original work is properly cited.

\section{INTRODUCTION}

Vegetables and fruits are not only the source of nutrition for human beings but also very important for maintaining health. Due to the presence of essential minerals and vitamins, the vegetables play a vital role in a diet of mankind1. They are an important source of vitamins, minerals, and fibers for human lives. However, vegetables are different from fruits due to their antioxidant activities as well as their fiber and vitamin contents. Vegetables are bioavailable because of the presence of antioxidants. Different vegetables show different antioxidant activities and provide protection against oxidative stress ${ }^{1}$. Vegetables and fruits contain a high concentration of antioxidants that help to treat many diseases such as aging, brain dysfunction, inflammation, heart disease, arteriosclerosis, arthritis, and cancer etc. The substance which has the capacity to prevent oxidative damage to fats, proteins and nucleic acid with the help of reactive oxygen species are known as antioxidants. These reactive oxygen species primarily are reactive free radicals including alkoxyl, peroxyl, hydroxyl, superoxide, and non-radicals, for example, hypochlorous, hydrogen peroxide ${ }^{2}$. Vegetables contain no of antioxidants such as vitamins $A, C$, and $E$ as well as carotene all of which play a vital role in good health. They also play a significant role in different mechanisms including co-factors for certain enzymes, involvement in oxidation and reduction reaction $^{3}$. In fruits and vegetables, three major groups are present which are ascorbic acid, phenolic compounds, and carotenoids. Beta carotenoids are responsible for the antioxidant defensive system. Ascorbic acid and phenolic 
compounds are also called hydrophilic antioxidants and carotenoids are called lipophilic antioxidants ${ }^{4}$. In the present review, a focus has been made on the nutritional and antioxidant value of four common vegetables i.e., Daucus carota (carrot), Cucurbita pepo Linn (pumpkin), Spinacia oleracea (spinach) and Solanum tuberosum (potato) (Figure 1).

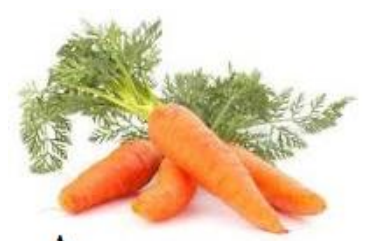

A

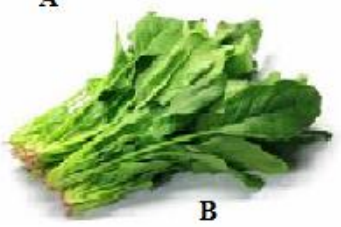

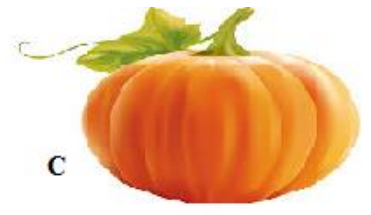

D

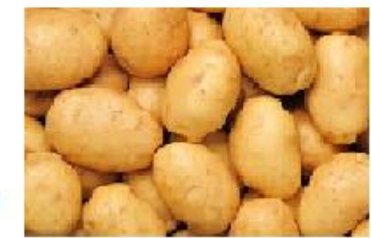

Figure 1. A: Daucus carota (carrot); B: Cucurbita pepo Linn (pumpkin); C: Spinacia oleracea (spinach); D: Solanum tuberosum (potato).

\section{Daucus carota $L$}

The most important crop of Apiaceae Family is Daucus carota commonly called carrot. Carrot is a root vegetable and has the worldwide distribution. Carrot shows different colors such as white, red, orange, yellow, purple and dark purple; yellow and purple colors carrot are the first cultivation of this family. Carrot is one of the most important vegetables all over the world and its phytochemicals and polynutrients are beneficial for mankind ${ }^{5}$. Carrots are rich in lipophilic and hydrophilic antioxidants and a good source of carbohydrates, vitamins, and minerals such as $\mathrm{Mg}, \mathrm{Ca}, \mathrm{P}$ and $\mathrm{Fe}^{6}$. It is also rich in carotenoids especially beta carotenoids. Due to the presence of vitamins and antioxidants carrot shows beneficial health effects on mankind as it possesses immune boosting, antioxidant and anti-carcinogenic properties. The chemical structure of carrot contains a polyene chain having 11 conjugated double bonds and a $\beta$-ring at each end of the chain ${ }^{7}$. Carrots on the basis of their nutrition are ranked on 38 number ${ }^{1}$. Nitrogen balance in our body and the quantity of urine can also be controlled by carrot ${ }^{8}$. Sometimes eyes photoreceptors start to deteriorate which is an eye vision problem due to the deficiency of Vitamin A. Beta carotenoid (the major source of vitamin A) in carrots helps to protect the vision and also provides protection against muscular degradation and the development of senile cataract, the leading cause of blindness in aged people. Carrots one of the richest sources of provitamin A and its high intake is associated with a significant decrease in postmenopausal breast cancer due to the presence of carotenoids. Carrot plays a vital role in human health because of enrichment of carotenoids and phenolic compounds which also reduce the risk of many diseases ${ }^{5}$.

\section{Cucurbita pepo Linn}

Pumpkin is the common name of Cucurbita pepo Linn which belongs to the cucurbitaceae family. Pumpkin is also called Elegede in Southwest and Nigeria regions. The word pumpkin is derived from a Greek word pepon which means a large melon. In the plant kingdom, this family is one of the largest families which consist of a large number of edible plant species ${ }^{9}$. In pumpkin family melon, cucumber, gourds and summer winter squash also included ${ }^{10}$. Pumpkin is used as food due to its high nutritional value as it contains a high level of carotenoids. Pumpkins have many varieties which are grown in Brazil11. Pumpkins are a good source of carotenoids, carbohydrates, vitamins, and other minerals ${ }^{12}$; they provide protection against many acute and chronic diseases due to the presence of B complex, calcium, and phosphorous ${ }^{13}$. After the nutritional analysis, it has been noted that pumpkin wastes (both peel and pulp) are the richest source of antioxidants, nutrients, polyphenol compounds, carotenoids dietary fiber, and minerals such as $\mathrm{P}$ and Fe. The pulp of pumpkin is comprised of the high level of beta carotenoids as well as many other vitamins. Pumpkin extract shows antioxidant activity, antimicrobial activity, as well as various other activities. This extract consists of active compounds having the ability to scavenge different free radicals ${ }^{12}$.

\section{Spinacia oleracea}

Spinacia oleracea (spinach) belongs to the family Amaranthaceae which has about 102 genera and 1400 species worldwide. It also belongs to the leafy green family. The word spinach has been derived from the Persian word ispanai which means the "green hand". In Latin, it is called spanachia and in English, it is called as 
spinach. The range of color of spinach is from light green to dark green. Spinach can be classified into two categories: spinach with crinkle leaf and the spinach with smooth leaf. Although there are a lot of varieties, however, all of these have many characters which are similar to each other ${ }^{14}$. Spinach is a leafy green vegetable and is a rich source of vitamins and antioxidants. It is not only a common raw material in the food processing industry but also finds importance as a dietary vegetable. Spinach is a good source of essential nutrients for example carotenoids, vitamins (vitamin A, C) and minerals $(P, K, M g)$. It also shows antioxidant and various activities but it does not exhibit hypolipidemic activity ${ }^{15}$. The leaf of this vegetable contains carotenoids, polyphenol, flavonoids, and ascorbic acid. Fresh spinach extract shows antioxidant and antimicrobial activities ${ }^{16}$.

\section{Solanum tuberosum}

The word potato is derived from Spanish word patatas and in English, it is called potato which grows down the earth about $6 \mathrm{~cm}$. It is the third most important crop in the United States. The production of potato crop is more than 300 million metric tons ${ }^{17}$. According to their shapes and color, it is categorized into many varieties which include round whites, yellow flesh, long whites, round red etc ${ }^{18}$. There are 5000 varieties of potatoes present in all over the world. The major variety of potato is solanum tuberosum which is a starchy vegetable and consist of alkaloids and flavonoids in a large amount. Potatoes are polynutrients and contain carbohydrates, dietary fiber, and some other minerals ( $\mathrm{K}, \mathrm{Mg}$, and Fe etc). It is used for allergic reactions as well as it plays a vital role in the production of the antioxidant defense system due to the presence of essential nutrients (vitamins, polyphenol, beta carotene, and minerals). Polynutrients in potatoes help in chronic and acute diseases ${ }^{18}$. One of the most important vitamins C (Ascorbic acid) in potatoes tuber has a significant role in human nutrition. The highest content of ascorbic acid (about $20.75 \mathrm{mg} / \mathrm{kg}$ ) is present in marble potato (a variety of potato) ${ }^{19}$. Potato nutrients also show a favorable impact on satiety, blood pressure, gut health and other acute and chronic diseases in children teen adults ${ }^{18}$.

\section{Comparative Studies}

Studies investigate that vegetables, such as pumpkin, spinach, shallots, potato, carrots, and cabbage, have high antioxidant activities. Beside antioxidant nutrients such as ascorbic acid, tocopherols, and carotenoids, these vegetables are also a good source of polyphenol components ${ }^{20}$. Among these vegetables, carrots show highest antioxidant activity followed by pumpkin, spinach, and potatoes. Carrot peel and juice are rich in pro-healthy antioxidants both of lipophilic (carotenoids) and hydrophilic (phenolic compounds) characters ${ }^{21}$. Pumpkin seeds have a high content of vitamin $E$ (tocopherol) 22 and the pulp was found to be a rich source of $\beta$-carotene (142.38 mg/100 gm). The peel and pulp samples present almost similar values of polyphenols and antioxidants ${ }^{23}$. Spinach is rich in antioxidants such as beta-carotene and lutein. These have antioxidant and anticancer properties ${ }^{24}$. Spinach is a rich source of polyphenols. It contains high levels of flavonols unique to spinach. They are mainly quercetagetin derivatives. Other compounds in spinach were scarcely studied, although some like $p$ coumaric acid contribute significantly to its antioxidant activity ${ }^{25}$. Potato is not only a source of antioxidants source such as ascorbic acid, tropocoal, phenolic acid and flavonoids in human diet but it consists of high amount of polyphenolic compounds. Potatoes are good sources of phenolic compounds, with total phenolic content higher than other widespread fruits and vegetables like carrots, pumpkin, or tomatoes because of their high consumption rates ${ }^{26}$. The aqueous and methanolic extracts of spinach (Spinacea oleracia), pumpkin (Cucurbita pepo), carrots and potatoes were evaluated for antimicrobial activity against bacterial strains ${ }^{27}$.

Potatoes exhibits well-known antimicrobial activity against different microbes. The methanolic and aqueous extracts of carrot (leaves, stems, and roots) on four microorganism species showed that the root, leaf, and stem were active against $B$. cereus, $S$. aureus, and $E$. coli; it shows that carrot shows maximum antimicrobial activity28. Leaves of Spinach was extracted with methanol extract. the extract of spinach $(20 \mathrm{mg} / \mathrm{ml})$ showed maximum activity against the Escherichia coli $(32 \mathrm{~mm})$, Staphylococcus aureus $(29 \mathrm{~mm})$ zone of inhibition respectively whereas the minimum activity is reported against the Bacillus subtilis 
(12mm) and Penicillium chrysogenum (15mm). Antimicrobial Activity of Pumpkin: The fruity body of Cucurbita pepo (pumpkin) was extracted with methanol extract. Methanolic extract of pumpkin shows the sufficient zone of inhibition against the microorganisms as $23 \mathrm{~mm}$ in Escherichia coli, $22 \mathrm{~mm}$ in Staphylococcus aureus ${ }^{29}$.

\section{CONCLUSIONS}

Vegetables contain many important antioxidants and nutrients. These antioxidants provide protection against diseases and reduce the rate of risk in mankind. The use of these vegetables helps to maintain the health of human being. Daucus carota $L$ is a good source of antioxidants, carbohydrates, vitamins, and minerals such as $\mathrm{Ca}, \mathrm{Mg}, \mathrm{P}$, and $\mathrm{Fe}$. It shows anti-carcinogenic, immune boosting properties and protection against muscular degradation. The Cucurbita pepo Linn (pumpkin) contains carotenoids, carbohydrates, vitamins, antioxidants, polyphenols, carotenoids, dietary fiber and minerals such as $\mathrm{P}$ and $\mathrm{Fe}$. Spinacia oleracea (spinach) is a good source of carotenoids, vitamins, and minerals ( $\mathrm{P}, \mathrm{K}, \mathrm{Mg})$. Its leaves contain carotenoids, polyphenols, flavonoids, and ascorbic acid. Solanum tuberosum (potato) is rich in starch, alkaloids, flavonoids, dietary fiber, and some other minerals $(\mathrm{K}, \mathrm{Mg}, \mathrm{Fe})$. Potato helps to overcome chronic and acute diseases and has an impact on blood pressure and gut health.

\section{REFERENCES}

1. Owolade SO, Akinrinola AO, Popoola FO, Aderibigbe OR, Ademoyegun OT, Olabode I. Study on physicochemical properties, antioxidant activity and shelf stability of carrot (Daucus carota) and pineapple (Ananas comosus) juice blend. Int Food Res J. 2017;24(2):534-40.

2. Rice-Evans C. Flavonoids in health and disease. Boca Raton: CRC Press; 2003.

3. Shetty A, Magadum S, Managanvi K. Vegetables as Sources of Antioxidants. J Food Nutr Disord. 2013;2(1):1-5.

4. Arshiya $S$. The antioxidant effect of certain fruits: $A$ review. 2013;5(12):265-8.

5. Da JC, Dias S. Nutritional and health benefits of carrots and their seed extracts. Food Nutr Sci. 2014;5(5):2147-56.
6. Sharma KD, Karki S, Thakur NS, Attri S. Chemical composition, functional properties and processing of carrot-a review. J. Food Sci Tech Mys. 2012;49:2232.

7. Augspole I, Rakcejeva T, Kruma Z, Dimins F. Shredded carrots quality providing by treatment with hydrogen peroxide. 9th Baltic Conference on Food Science and Technology. Food for Consumer WellBeing. FOODBALT 2014, Jelgava, Latvia. 2014;2014:150-4.

8. Noella J, Umuhoza $\mathrm{K}$, Sylvestre $\mathrm{H}$, Philippe $\mathrm{S}$. Nutritional quality of carrot (Daucus carota L.) as influenced by farmyard manure. WJAS. 2014;2(5):102-7.

9. Oloyede F. Growth, yield and antioxidant profile of pumpkin (Cucúrbita pepo L.) leafy vegetable as affected by NPK compound fertilizer. J Soil Sci plant Nutr. 2012;12(3):379-88.

10. Bratsch A. Specialty crop profile: horseradish. Virginia Coop Ext. 2009;10.

11. Nawirska-Olszanska A, Kita A, Biesiada A, SokolLetowska A, Kucharska AZ. Characteristics of antioxidant activity and composition of pumpkin seed oils in 12 cultivars. Food Chemistry. 2013;39:155-61.

12. Mala S. Nutritional composition and antioxidant activity of pumpkin wastes. Int $\mathrm{J}$ Pharm Chem Biol Sci. 2016;6(3):336-44.

13. Priori $D$, Valduga E, Castelo J, Villela B, Mistura CC, Vizzotto $M$, et al. Characterization of bioactive compounds, antioxidant activity and minerals in landraces of pumpkin (Cucurbita moschata) cultivated in Southern Brazil. Food Sci Tecnhology. 2016;37(1):1-8.

14. Kiple KF, Ornelas KC. Cambridge world history of food. United Kingdom: Cambridge, 2002; 1857: 288.

15. Chu Y, Sun J, Wu X, Liu RH. Antioxidant and antiproliferative activities of common vegetables. J. Agric. Food Chem. 2002;50(23):6910-6916.

16. Ligor M, Trziszka T, Buszewski B. Study of antioxidant activity of biologically active compounds isolated from green vegetables by coupled analytical techniques. Food Anal. Method. 2013;6:630-6.

17. Camire ME, Kubow S, Donnelly DJ. Critical reviews in food science and nutrition potatoes and human health potatoes and human health. Crit Rev Food Sci Nutr. 2009;49:823-40.

18. Zaheer $\mathrm{K}$, Akhtar MH. Potato production, usage, and nutrition-A review. Crit Rev Food Sci Nutr. 2016; 56(5):711-21. 
19. Love SL, Salaiz T, Mosley AR, Shafii B, Price WJ, Thornton RE. Ascorbic acid concentration and stability in North American potato germplasm. Acta Hortic. 2003;619:87-93.

20. Ismail A, Marjan ZM, Foong CW. Total antioxidant activity and phenolic content in selected vegetables. Food Chem. 2004;87(4):581-6.

21. Hager TJ, Howard LR. Processing effects on carrot phytonutrients. In Hort Science. 2006;41(1):74-9.

22. Nor N, Carr A, Hardacre A, Brennan C. The development of expanded snack product made from pumpkin flour-corn grits: effect of extrusion conditions and formulations on physical characteristics and microstructure. Foods. 2013;2(2):160-9.

23. KwonYI, Apostolidis E, Kim YC, Shetty K. Health benefits of traditional corn, beans, and pumpkin: in vitro studies for hyperglycemia and hypertension management. J. Med. Food. 2007;10(2).

24. Hatamjafari F, Tazarv VM. Study of antioxidant activity of Spinacia oleracea L. OJC. 2013;29(2):4515.

25. Bajcan D, Tomas J, Uhlirova G, Árvay J, Trebichalsky $P$, Stanovic R, Simansky V. Antioxidant potential of spinach, peas, and sweetcorn in relation to freezing period. Czech J.Food Sci. 2013;31:613-8.

26. Akyol H, Riciputi Y, Capanoglu E, Caboni MF, Verardo V. Phenolic compounds in the potato and its byproducts: An overview. Int. J. Mol. Sci. 2016;17(6):835.

27. Routray R, Kar M, Sahu RK. Evaluation of an antioxidant potential in selected leafy vegetables of Odisha, India. Int J Pharm Pharm Sci. 2013;1(4):21-7.

28. Dib MA, Bendahou M, Bendiabdellah A, Djabou N, Allali $\mathrm{H}$, Tabti $\mathrm{B}$ et al. Partial chemical composition and antimicrobial activity of Daucus crinitus Desf. extracts. Grasasy Aceites. 2010;61(3).

29. Routray R, Kar M, Sahu RK. Evaluation of an antioxidant potential in selected leafy vegetables of Odisha, India. Int. J. Pharm. Pharm. Sci. 2013;5(1):232-35. 